\title{
Some observations on the reproductive biology of the scuttle fly Megaselia andrenae (Diptera: Phoridae) at the nesting site of its host Andrena agilissima (Hymenoptera: Andrenidae)
}

\author{
CARLo POLIDORI ${ }^{1 *}$, R. HenRy L. DISNEY ${ }^{2}$ and Francesco ANDRIETTI ${ }^{1}$ \\ ${ }^{1}$ Università degli Studi di Milano, Dipartimento di Biologia, Sezione di Zoologia e Citologia, via Celoria, 26, 20133 Milano, Italy; \\ e-mail: cpolidori@virgilio.it, francesco.andrietti@unimi.it \\ ${ }^{2}$ University of Cambridge, Department of Zoology, Downing Street, Cambridge CB2 3EJ, UK; e-mail: rhld2@hermes.cam.ac.uk
}

Key words. Behaviour, reproduction, kleptoparasitism, Megaselia andrenae, Andrena agilissima

\begin{abstract}
Some behavioural aspects of the reproductive biology of Megaselia andrenae Disney, a kleptoparasite of the communal bee Andrena agilissima (Scopoli), were investigated at the nesting site of its host at Isola d'Elba (Italy). The scuttle fly mates more often in the early afternoon, which coincides with the period when the provisioning flights of its host are more frequent. The presence of the flies at the host nesting site, either in copula or single, is lower in the morning. In general only the females enter the host nests immediately after a mate, in a few cases closely followed by the males. When leaving the nest, females refuse to mate again with the males waiting outside. Observations on the ovaries of the females revealed no differences, either in the number of eggs or in the length of the most mature egg, between the individuals collected in copula or when flying alone. The species is sexually dimorphic, the females being larger than males. Male size does not seem to influence the females choice for mating.
\end{abstract}

\section{INTRODUCTION}

Probably due to the frequent matings that occur at the host nesting site, many biological observations made on scuttle flies (Diptera: Phoridae) concern some aspects of their reproductive biology, in particular courtship and copulatory behaviour (Miller, 1984; Sivinski, 1988; Wcislo, 1990; Disney et al., 2000).

The genus Megaselia Rondani presents a wide range of larval feeding habits, which include species that are generalised scavengers, predators, parasitoids, parasites or kleptoparasites (Robinson, 1971; Binns, 1980; Disney, 1994). Some species of Megaselia associated with Hymenoptera are kleptoparasites, and their putative hosts seem to be solitary or presocial bees and wasps such as Andrenidae, Megachilidae, Crabronidae and Pompilidae (e.g. Collart, 1933; Krombein, 1967; Disney, 1994; Polidori et al., 2001).

Megaselia andrenae Disney is a recently described species that was named after its association with the communal andrenid bee Andrena agilissima (Scopoli) in Italy (Disney et al., 2000). The aim of the present paper is to extend preliminary observations on the reproductive biology of this species, which appears to be a kleptoparasite of pollen balls stored by the bees (Disney et al., 2000). The previous work reported a few observations of flies in copula in the vicinity of bees nest entrances: on separation from the male a female typically entered a nest entrance.We give here more detailed information about the biology of the species, including the fly's diurnal activity presence and distribution along with some morphological data that could be related to the observed reproductive behaviour.

\section{MATERIALS AND METHODS}

The study was carried out in May 2002 and May 2003 at Colle Palombaia (Campo nell'Elba, Isola d'Elba, Italy), during the highest activity period of $A$. agilissima, the host bee of $M$. andrenae. The A. agilissima nesting site is located in a large earth wall ( $3 \mathrm{~m} \times 16 \mathrm{~m}$ were colonized by the bees in 2003 , with the highest nest density in a central area of $6 \mathrm{~m} \times 2.5 \mathrm{~m}$ ). The general configuration of the nesting area may was described by Giovanetti et al. (1999). We selected small parts of this nesting area: $1 \mathrm{~m} \times 1.5 \mathrm{~m}$ (which included about 20 bee nest entrances) in 2002 and $1 \mathrm{~m} \times 3 \mathrm{~m}$ (which included 189 counted nest entrances) in 2003. In 2002, the "small area" was used for recording both the activity and the behaviour of the flies; in 2003 it was used for recording kleptoparasite and host bee parallel activities, while the overall behaviour of the flies was also investigated by patrolling the whole nesting site $(16 \mathrm{~m} \times 3 \mathrm{~m})$. This area will be called "whole area".

In 2002, in each day of the 10 days observation period (May $6^{\text {th }}-19^{\text {th }}$, not including the $8^{\text {th }}-10^{\text {th }}$ and $12^{\text {th }}$, in which no observation was made even if flies were present at the site), we recorded the presence and behaviour of scuttle flies at the bee aggregation. In that year, observations and flies collections were made twice a day: from 9.30 to 11.00 and from 12.30 to 14.00 (solar hours).

In $2003\left(4^{\text {th }}-15^{\text {th }}\right.$ May), we recorded the daily activity and presence of the flies during an extended diurnal interval (6.00-19.00, solar hours): we recorded in the early morning (6.00-7.00) and in the late afternoon (18.00-19.00) the presence of the flies patrolling the whole area, and the presence of the "mating balls" (see Results) patrolling the whole area for 30 minutes from 7.00 to 17.00 (hours indicating the start of the first and the last half-hour patrolling); more detailed information of the flies' activity was recorded every two hours for 30 minutes (from 7.00 to 17.00 , hours indicating the start of the first and the last half-hour patrolling), counting the passages of the flies for 5 minutes on each of 6 "subzones" $(1 \mathrm{~m} \times 0.5 \mathrm{~m})$ in which was divided the small area; a synchronous count of the number of visits (in their nests) by $A$. agilissima females was performed.

In 2002, we collected two kinds of samples: flies flying alone across the host aggregation (ALONE), and pairs of

\footnotetext{
* Corresponding author.
} 


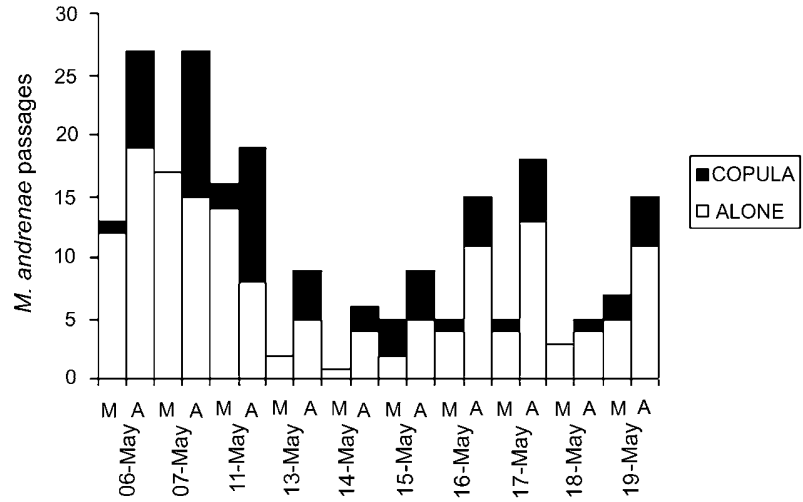

Fig. 1. Number of passages of Megaselia andrenae, either ALONE or COPULA, in the two daily periods of observation in $2002(\mathrm{M}=9.30-11.00 ; \mathrm{A}=12.30-14.00)$.

males/females flying in copula (COPULA). From a total of 73 individuals (21 COPULA pairs and 31 ALONE) we measured the length of the hind femur for each fly, counted the eggs (only mature eggs, easy to distinguish from the preceding oocytes for their more elongated shape and by the presence of a fully formed chorion) in each female's ovaries, and we measured the length of the most mature egg.

Data were analysed using non-parametric statistics (Wilcoxon test, Mann-Whitney test and Spearman correlation test), when concerned with estimation of flies general abundance at the nesting site in different periods of the day, to test differences in the abundance of flies categories (single specimens and pairs in copula) and to test the correlation between the activity distribution of categories (flies and host bees). Sets of data concerning flies morphological traits were analysed with parametric statistics (Student's t-test), to test differences of observed mean values by chosen categories (males and females; single specimens and pairs in copula). A simple regression was used to test the correlation between size parameters of two categories (males and females collected in copula).

\section{RESULTS}

We recorded the time for every passage of a $M$. andrenae specimen (ALONE) or a pair of specimens in copula TABLE 1. Megaselia andrenae recorded passsages.

\begin{tabular}{|c|c|c|c|}
\hline \multicolumn{4}{|c|}{ Number of recorded passages } \\
\hline \multicolumn{3}{|l|}{ May 2002} & \\
\hline Observation period & ALONE & COPULA & \\
\hline $9.30-11.00$ & 64 & 10 & \\
\hline $12.30-14.00$ & 95 & 55 & \\
\hline TOTAL & 159 & 65 & \\
\hline \multicolumn{4}{|l|}{ May 2003} \\
\hline \multirow[t]{4}{*}{ Observation period } & \multicolumn{2}{|c|}{ ALONE + COPULA } & $\begin{array}{c}\text { MATING } \\
\text { BALLS }\end{array}$ \\
\hline & & WHOLE & WHOLE \\
\hline & SMALL & NESTING & NESTING \\
\hline & AREA & AREA & AREA \\
\hline $6.00-7.00$ & - & 4 in $1 \mathrm{~h}$ & 0 in $1 \mathrm{~h}$ \\
\hline $7.00-12.00$ & 504 in $41.5 \mathrm{~h}$ & - & 23 in $41.5 \mathrm{~h}$ \\
\hline $12.00-18.00$ & 493 in $33 \mathrm{~h}$ & - & 59 in $33 \mathrm{~h}$ \\
\hline $18.00-19.00$ & - & 35 in $1.5 \mathrm{~h}$ & 2 in $1.5 \mathrm{~h}$ \\
\hline TOTAL & 997 in $75.4 \mathrm{~h}$ & 39 in $2.5 \mathrm{~h}$ & 74 in $77 \mathrm{~h}$ \\
\hline
\end{tabular}

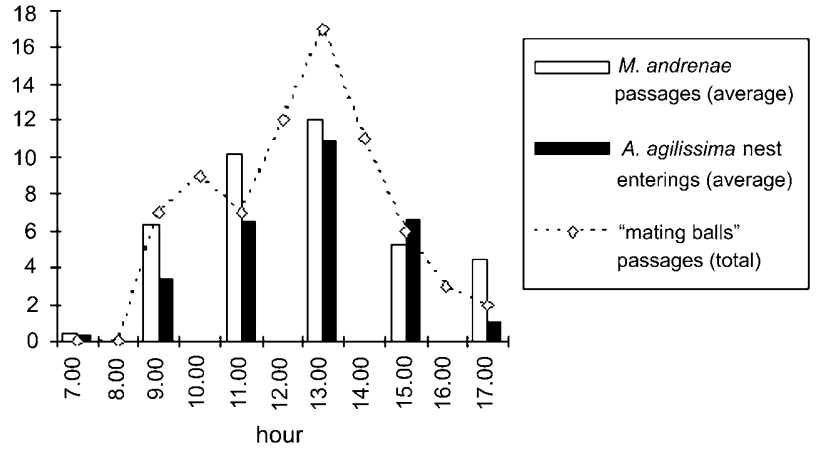

Fig. 2. Daily distributions of Megaselia andrenae activity (average number of recorded passages), of Andrena agilissima activity (average number of recorded visits to the nests) and of total number of recorded passages of $M$. andrenae "mating balls" in 2003. For the M. andrenae and A. agilissima distributions, the hours indicate the starting of the half-hour record of passages in the small area, made every two hours (e.g. $7.00=$ 7.00-7.30) (see also Materials and Methods); for the "mating balls" distribution, the hours indicate the starting of the halfhour patrolling of the nesting site, made every hour (see also Materials and Methods).

(COPULA) observed flying across the observation area. Each of these passages should be considered as a unit of both categories (ALONE or COPULA) (Table 1). In 2003, also the presence of a third category was recorded, the "mating ball" (a group of females and males flying very close one to the other and that typically produce copulae): a "mating ball" is considered as a special unit. The total number of recorded passages was 224 from 30 observation hours in 2002 and 1110 from 77 observation hours in 2003 (997 for 74.5 hours in the smaller area and 39 by patrolling for 2.5 hours the whole nesting site in the early morning and in the late afternoon, plus 74 passages of "mating balls" during the 77 hours of observation).

Fig. 1 shows the distribution of the passages in the 10 days of observations for 2002 (small area). Wilcoxon tests for paired data show that the COPULA passages were significantly higher in the afternoon $\left(\mathrm{T}=0 ; \mathrm{n}_{1}=\mathrm{n}_{2}=10 ; \mathrm{P}=0.00506,<0.01\right)$, while ALONE passages did not differ significantly between time periods $\left(T=8.5 ; n_{1}=n_{2}=10 ; P=0.052, n s\right)$. Tab. 1 resumes the numbers of recorded passages. Over the entire day, flies were more often recorded ALONE than in COPULA (Wilcoxon test; $\left.\mathrm{T}=12.5 ; \mathrm{n}_{1}=\mathrm{n}_{2}=20 ; \mathrm{P}=0.00055,<0.001\right)$.

In 2003 (Fig. 2), the number of recorded passages (small area) (ALONE + COPULA, we did not divide the two sets of data during the 2003 observations) was, on average, lower in the morning (7.00-12.00) than in the second period of observation $(12.00-18.00)$ (average $_{(7.00-12.00)}=6.07$ passages per patrolling; average $_{(12.00-18.00)}=7.46$ passages per patrolling; MannWhitney's $U=2076, \mathrm{n}_{(7.00-12.00)}=83, \mathrm{n}_{(12.00-18.00)}=66 ; \mathrm{P}=0.0109$, $<0.05$ ). "Mating balls" too were recorded, on the whole (whole area), more frequently in the afternoon $(6.00-12.00$ : number of passages per hour $=0.54 ; 12.00-19.00$ : number of passages per hour $=1.77$ ).

Fig. 2 shows also that there is a general match between the daily distribution of activity in flies and the host bees, when the latter is calculated as the number of visits of the bees to their nests. A significant linear correlation was found between the recorded flies' passages and the recorded bee's nest enterings through the day (Spearman rank correlation test; $\mathrm{r}=0.35 ; \mathrm{n}=$ $\left.143 ; \mathrm{P}=1.21 \times 10^{-5},<0.001\right)$. However, $M$. andrenae (Table 1) was recorded at the nesting site of $A$. agilissima since the early morning (number of recorded passages between 6.00 and 7.00: 4 
TABLE 2. Biometrical characters of Megaselia andrenae collected specimens (2002).

\begin{tabular}{lcc}
\hline & COLLECTED SPECIMENS & COPULA \\
\hline $\begin{array}{l}\text { Number of collected specimens } \\
\begin{array}{l}\text { Egg number } \\
\text { (female specimens) }\end{array}\end{array}$ & $31(26$ males, 5 females $)$ & 21 (pairs) \\
$\begin{array}{l}\text { Most mature egg length }(\mathrm{mm}) \\
\text { (female specimens) }\end{array}$ & $15.80(\mathrm{SD}=4.147 ; \mathrm{n}=5)$ & $18.75(\mathrm{SD}=7.833, \mathrm{n}=20)$ \\
$\begin{array}{l}\text { Hind femur length }(\mathrm{mm}) \\
\text { (female specimens) }\end{array}$ & $0.490(\mathrm{SD}=0.024 ; \mathrm{n}=5)$ & $0.491(\mathrm{SD}=0.022 ; \mathrm{n}=20)$ \\
$\begin{array}{l}\text { Hind femur length }(\mathrm{mm}) \\
\text { (male specimens) }\end{array}$ & $0.924(\mathrm{SD}=0.125 ; \mathrm{n}=5)$ & $0.979(\mathrm{SD}=0.080 ; \mathrm{n}=21)$ \\
\hline
\end{tabular}

in 1 hour of observation) and until the late afternoon (number of recorded passages between 18.00 and 19.00: 35 in 90 minutes of observation), while in these two periods of the day no bees were recorded to enter their nests.

The typical behaviour of $M$. andrenae at the host nesting site is summarized as follows: females as well as males fly across the aggregation very close to the soil surface, sometimes landing on the ground. Subsequently, a male joins a female to copulate. In most cases, females seem to depend on a male to enter a nest shortly after the copula: in 2002 we did not record any female that entered a nest without any observed previous copula $(\mathrm{n}=$ 26), and in 2003 entering without previous copulation was observed 58 times out of 202 recorded nest visits by the flies.

The mated pair flies slower than single flies, sometimes landing very close to a host nest entrance. In such case, either the couple remains paired and resumes its flight or the pair splits up. After separating, the female always enters the host nest ( $\mathrm{n}=$ 170 out of 170 cases), while the male generally remains on the ground where he separates from the female or flies away rapidly. Rarely, he enters the nest closely following the female. We were able to follow 141 sequences (out of 170 observed splits of the copulae close to a bee nest entrance) until the female re-emerged from the host nest. If the male did not enter the nest, he remained waiting at the nest entrance ( 90 out of 141 cases) trying to mate again when the female emerged (90 of 90 cases) or he flew away shortly after female entrance (39 of 141 cases). If the male entered the nest (12 of 141 cases), he emerged a few seconds later (2-7 seconds) and stopped close to the nest entrance. Even in these last 12 cases, the male tried to copulate again when the female emerged from the bee nest.

Females remained in the host nest from 3 to 884 seconds $(\overline{\mathrm{x}}=$ 241.4; $\mathrm{SD}=203.5 ; \mathrm{n}=141$ ) and, on emerging from the nest, they never mated again with the males waiting outside, rejecting their courtship attempts and flying away.

In 16 out of 228 recorded visits of flies' females to the nests, we observed a second female entering a host bee nest already occupied by another female fly; in 4 cases, the number of females simultaneously visiting the same nest was 3 , and in 2 cases was 4 . In 77 out of 141 cases, one or more bees were recorded entering and coming out from their nests different times while a fly female was still inside.

We were unable to identify the sex of the flies directly in the field, and the only way to do it was that to determine collected specimens. Of the 31 ALONE collected flies, 26 were males (7 collected in the morning and 19 in the afternoon) and 5 were females ( 1 collected in the morning and 4 in the afternoon) (Table 2). If we add to them the 21 collected COPULA (one in the morning, 20 in the afternoon), we obtain a total of 47 collected males and 26 collected females.
The collection of the $M$. andrenae individuals permitted analysis of additional aspects of their reproductive biology (Table 2). Since we collected both ALONE and COPULA females, we were able to test the difference in the reproductive status of these two groups of females. The selected parameters were the number of the mature eggs present in the ovaries and the length of the most mature egg. The differences between the means of both these parameters at the $\mathrm{P}=0.05$ level when tested with a Student's t-test, were not significant. In one case, we collected a female in copula with very immature eggs (oocytes), that we did not count and measure. In other words, the degree of egg development does not seem to influence the occurrence of matings (COPULA).

Hind femur length has been demonstrated to be a good parameter to evaluate the body size in scuttle flies (Disney, 1997).We measured the length of the hind femurs of males and females in an attempt to verify the presence of sexual dimorphism in $M$. andrenae and to test for size preference in the choice of a partner. Females are larger than males, since their hind femur lengths (average $=0.968 \mathrm{~mm} ; \mathrm{SD}=0.091 ; \mathrm{n}=26$ ) were significantly longer (Student's t-test; $\mathrm{t}=-3.753$; $\mathrm{dgf}=71$; $\mathrm{P}=0.00035,<0.001$ ) than those of males (average $=0.879 \mathrm{~mm}$; $\mathrm{SD}=0.101 ; \mathrm{n}=47$ ). No significant differences were found in femur lengths between COPULA and ALONE males or females, and no correlation resulted from a simple regression analysis between hind femur length of males and females of the 21 pairs collected in copula $(\mathrm{r}=0.018 ; \mathrm{n}=21 ; \mathrm{P}=0.937 ; \mathrm{ns})$.

\section{DISCUSSION}

M. andrenae was shown to be active at the bee nesting site throughout the whole day, from 6.00 to 19.00. Even if our 2002 and 2003 data were confined to the first two weeks of May, previous findings (Disney et al., 2000) confirm its presence throughout the whole month.

Matings of $M$. andrenae are more frequent in the early afternoon: this fact could have its origin in the provisioning activity of the host bee (number of bee enterings with pollen), which is higher in that period (Polidori et al., unpublished) and it is more likely to find open cells, since nest plugs are not yet set in. However, even considering only the general activity of the host bees (number of visits in the nests with or without pollen), one notes that it matches that of $M$. andrenae through the day (Fig. 2).

Notwithstanding that in 2003 we did not collect separately the data concerning ALONE and COPULA presences, we may confirm the afternoon-shifted matings by recording the "mating balls", a common way to produce copulae, were recorded more frequently in that period of the day.

Males often ( $n=102$ out of 141 cases) waited outside the nests for re-emergent females, sometimes after having followed 
them quickly in the bee nests ( $\mathrm{n}=12$ out of 102 cases). The persistent presence of the males of Megaselia close to bee's nests should not be considered as a control/disturb pattern in respect of bees returning to their nests (to allow female flies to complete her oviposition), since often one or more bees were seen entering their nests in spite of the presence of the males close to the entrance. It is possible that this behaviour of males, allows them to get more likely a second mating (not immediately after the female's coming out, as seen previously) than if they look for them randomly.

The present results complete and extend those sketched in previous unpublished observations (1992-1993) and in 1997 (Disney et al., 2000), which were based on a few specimens only at the same host aggregation. However, in 2002 we did not observe any case of an "aggregated mating system" (= "mating balls": a number of males and females that fly close to each other and then copulate) as described by Thornhill \& Alcock (1983), Sivinski (1988), Disney (1994, pp. 154-160), and by some of us in 1993 (unpublished) and in 1997 (Disney et al., 2000) for this same species. Instead, in 2003, 74 "mating balls" passages were recorded throughout the nesting site. The different results about the presence of the "mating balls" in 2002 and 2003 could be related to the density of individuals of $M$. andrenae at the nesting site in the two years. In fact, the recorded number of passages (ALONE + COPULA) $/\left(\right.$ hour $\times \mathrm{m}^{2}$ ) (small area) in 2003 is much higher than in the previous year (4.98 in 2002 against 26.76 in 2003).

Frequent matings were also observed by Wcislo (1990) for the scuttle fly Phalacrotophora halictorum (Melander and Brues) at a nesting aggregation of the bee Lasioglossum figueresi Wcislo, while the matings at such sites seem to be very rare in $M$. oxybelorum Schmitz, observed by Polidori et al. (2001) at a nesting site of the solitary wasp Cerceris arenaria (Linnaeus). However, M. oxybelorum was frequently observed to mate close to nests entrances in an aggregation of another solitary ground nesting sphecid wasp, the beewolf Philanthus triangulum (Fabricius) (Polidori et al., unpublished). In the present case, females in general entered the host nest immediately after a mate, having reached the nest in copula. In the cases when we did not see the copula reaching a nest (and we recorded only the female entering the nest), maybe the split of the copula occurred before the start of observations. No coupled pair ever entered a nest.

Sexual dimorphism is characteristic of most species of scuttle flies. Indeed, in some species it is expressed not only by a size difference, but by other characters as well as the presence or absence of wings (e.g. Binns, 1980; Wcislo, 1990; Disney, 1994). The difference between male and female size (hind femur length) has been confirmed in the present finding. However, the choice of males by the females for the mating seems to be independent of their body dimension.

ACKNOWLEDGEMENTS. We thank C. Papadia, U. Romanò, A. Sandionigi, F. Torres and M. Giovanetti for their assistance during the field observations. Useful comments came from J. Asís and J. Tormos (University of Salamanca, Spain). Thanks are even due to one of the reviewers of the present paper, for many valuable suggestions he gave to improve the work. Great part of the present work was supported by a three years grant FIRB (Fondo per gli Investimenti della Ricerca di Base) RBAU019H94-001 (2001). RHLD's studies of Phoridae were funded by the Isaac Newton Trust (Trinity College, Cambridge).

\section{REFERENCES}

BinNs E.S. 1980: Mating behaviour, fecundity and feeding in the mushroom phorid, Megaselia halterata (Wood) (Dipt.). Entomol. Mon. Mag. 116: 45-58.

Collart A. 1933: Diptères élevées des nids de guêpes. Bull. Mus. R. Hist. Nat. Belgique 9: 1-8.

Disney R.H.L., Scanni B., Scamoni E. \& Andrietti F. 2000: A new species of scuttle fly (Diptera: Phoridae) whose larvae are kleptoparasites of a bee (Hymenoptera: Andrenidae). $G$. Ital. Entomol. 9: 99-104.

Disney R.H.L. 1994: Scuttle Flies: The Phoridae. Chapman \& Hall, London, xii +467 pp.

DisNeY R.H.L. 1997: Post-eclosion heterochrony in the maturation of the adult females of a termitophilous fly (Diptera: Phoridae). Bonn. Zool. Beitr. 47: 77-86.

Giovanetti M., Andrietti F., Martinoli A. \& Rigato F. 1999: Evidence of entrance sharing and subterranean connections in Andrena agilissima (Hymenoptera: Andrenidae). J. Insect Behav. 12: 423-431.

Krombern K.V. 1967: Trap-Nesting Wasps and Bees: Life Histories, Nests, and Associates. Smithsonian Press, Washington, D.C., 1 unnumbered plate, iii-vi +570 pp.

MiLLER P.L. 1984: Alternative reproductive routines in a small fly, Puliciphora borinquenensis (Diptera: Phoridae). Ecol. Entomol. 9: 293-302.

Polidori C., Disney R.H.L. \& Andrietti F. 2001: Some behavioral observations on Megaselia oxybelorum (Diptera: Phoridae), a new kleptoparasite of Cerceris arenaria (Hymenoptera: Sphecoidea: Philantidae). Br. J. Entomol. Nat. Hist. 14: 93-95.

Robinson W.H. 1971: Old and new biologies of Megaselia species (Diptera, Phoridae). Studia Entomol. 14: 321-348.

SIVINSKI J. 1988: Unusual female-aggregated mating systems in phorid flies. J. Insect Behav. 1: 123-128.

THORNhILl R. \& Alcock J. 1983: The Evolution of Insect Mating Systems. Harvard University, Cambridge, Mass. \& London, $547 \mathrm{pp}$.

WCISLO W.T. 1990: Parasitic and courtship behavior of Phalacrotophora halictorum (Diptera: Phoridae) at a nesting site of Lasioglossum figueresi (Hymenoptera: Halictidae). Revta Biol. Trop. 38: 205-209.

Received April 1, 2003; revised January 14, 2004; accepted February 17, 2004 